\title{
Colour Change in Heated Concrete
}

\author{
Izabela Hager*, Institute of Building Materials and Structures, Cracow \\ University of Technology, ul. Warszawska 24, 31-155 Cracow, Poland
}

Received: 17 May 2011/Accepted: 27 December 2012

\begin{abstract}
This paper presents an analysis of colour change in concrete under the influence of heat. The colour change observed in concrete is primarily a result of the gradual dehydration of the cement paste, but also of transformations occurring within the aggregate. The colour change may be used to reveal the exposure temperature of concrete from which the corresponding fire damage of concrete can be estimated. The paper presents the results of tests carried out on ordinary and high performance concretes (OC and HPC) prepared with natural river-bed aggregates. In addition, mortars and cement pastes prepared with the same components were observed to change colour upon heating. The colour change was investigated using Scion Image v. 4.0.3, an image analysis software package (Scion Corporation (C), USA). In the proposed method the digital image is split into three RGB colour components: red, green and blue, which are then presented as a histogram using counts of pixel intensity. The histogram results show colour distributions in unheated cementitious material and in material heated to temperatures ranging from $100^{\circ} \mathrm{C}$ to $1000^{\circ} \mathrm{C}$. The concrete colour changes as a result of heating are linked to the physical and chemical transformations taking place in the heated material.
\end{abstract}

Keywords: Concrete, High temperature, Colour change, RGB, Flatbed scanner, Digital image analysis

\section{Introduction}

In most cases when concrete is heated, a decrease of mechanical properties occurs causing the reduction of bearing capacity of a concrete element $[1,2]$. During a fire the temperature rises up to about $1200^{\circ} \mathrm{C}$. The temperature progress in fire is variable, so a characteristic curve representing the temperature evolution was developed on the basis of the real fire curves. In the first $5 \mathrm{~min}$ of the fire, according to the ISO834 characteristic curve (given by the EN 1991 Part 1.2), the temperature reaches almost $600^{\circ} \mathrm{C}$ and the heat spreads progressively deeper into the concrete element. However, concrete is a construction material with a relatively low thermal conductivity coefficient, thus heat in this material spreads slowly, and a significant thermal gradient may occur within the concrete element. Moreover, due to the difference of temperature between the exposed surface and the inside of the element, it should be assumed that a damage gradient may occur in concrete element. The assessment of the residual capacity of concrete structures seems to be a complex task, its complexity mainly attributable to the heterogeneity of concrete and the irregular distribution of damage induced by fire.

\footnotetext{
* Correspondence should be addressed to: Izabela Hager, E-mail: ihager@pk.edu.pl
} 
The assessment of fire damage in concrete structures usually starts with a visual evaluation, which consists in seeing whether there are changes caused by heat exposure. In order to simplify this task, a four-degree classification of damage to beams, columns and slabs has been developed, which includes usual repair methods for each class of damage [1, 2]. The methods of fire damage assessment applied to concrete structures are: in situ and laboratory methods, which provide the information required to evaluate the residual bearing capacity of the concrete element. Most of the in situ techniques used to assess the condition of concrete after exposure to fire are well-known methods, widely used to determine the properties of concrete in structures. These methods include the Schmidt rebound hammer, Ultrasound Pulse Velocity (UPV), Windsor probe, BRE internal fracture, and others [1-3]. In the cases of fire damage, laboratory techniques are also frequently used to assess concrete integrity. These tests require sampling of material and laboratory testing. The tests carried out on concrete core samples are designed to determine the residual mechanical properties of the damaged concrete (direct method) or to asses the temperature to which the concrete was exposed during the fire (indirect method). Such tests include [1-3] the resonance frequency method, ultrasound method, DTA, TGA, X-ray diffraction, scanning microscopy, thermoluminescence, chemical or petrographic analyses, and colourimetry. This last method is an indirect method that uses the fact that when material, in particular concrete, is heated, its colour changes.

The goal of the indirect fire damage assessment procedure with the use of colourimetry is to determine the temperature distribution within the element. The colour change may be a valuable tool in the determination of the temperature profile. Therefore, actions were taken to develop a method allowing the determination of the temperature profile within the heated element with the use of colour analysis.

\section{Application of Colour Change in Fire Sciences}

There are several research fields in the fire sciences that use colourimetry and the physical phenomenon of the colour change of solids resulting from heating. In the wildfire literature (e.g. [4, 5]), it was reported that physical and chemical transformations occurring at the soil surface during a fire bring about colour changes. The maximum temperature and duration of exposure were estimated by colour analysis. In this research the CR-300 colorimeter was employed along with the Munsell colour system to evaluate the changes of the chromas and hues of heated soils [4]. The changes in colour due to the exposure of building materials to heat are a well known phenomenon widely documented in the literature on the subject. The colour of natural stones change, as was shown in the research carried out by the Building Research Establishment ([5], summarized in [6]) and significant colour changes in stones containing minerals with iron compounds were reported. Changes in the colour of historical monuments built of sandstone when they are exposed to fire were also confirmed recently by Hajpal [7]. 
The intensity of colour change in heated concrete in turn depends on the type of aggregates chosen for its production. It is generally agreed [8] that concrete containing silicate aggregates (quartz, flint) will turn red when heated to a range of $300^{\circ} \mathrm{C}$ to $600^{\circ} \mathrm{C}$. Moreover, cement matrix in temperature between $600^{\circ} \mathrm{C}$ and $900^{\circ} \mathrm{C}$ will turn whitish-grey, and heating it to between $900^{\circ} \mathrm{C}$ and $1000^{\circ} \mathrm{C}$ gives a buff colour. Colour changes caused by temperature within construction concrete are easy to identify by means of visual comparison with concrete unaffected by high temperature [9].

The existing technique of rough estimation of the temperature to which concrete was subjected involves an inherently subjective visual colour analysis. In order to describe concrete colour changes in a more precise manner, a variety of colour description techniques are used [8, 10, 11, 12]. In the tests conducted by Faure and Hemond (described in LCPC [1, 13]) a spectrophotometer was used directly on the surface of concrete samples. Similarly, a spectrophotometer was used in the research of Annerel et al. [12] to analyse the colour of heated concrete ground into powder. The method used by Short [8] consisted in observing samples through a polarising microscope equipped with a colour analysis software package. The technique proposed by Felicetti [10] employs a general purpose digital camera for taking pictures and analysing the colour changes of concrete depending on the temperature reached. The latter method, however, requires consistent lighting, which is not easy to achieve. A dark room is required, and the white balance of the camera has to be adjusted [11].

Recently, the author proposed a technique [14] in which a flatbed scanner is used to obtain constant lighting conditions while pictures of concrete samples are taken. No expensive measurement equipment and/or colour analysis computer software is necessary to perform these observations. In this method, pictures are taken with a general-purpose flatbed scanner (HP Scanjet G2410) and analysed using an image analysis software package (Scion Image, version 4.0.3, Scion Corporation (C), USA).

The publication papers mentioned above $[1,2,8,10,11,12,13]$ agree that the colour change of material is a valuable source of information on the maximum temperature exposure and offers an alternative approach to the assessment of concrete damage due to fire action.

In general, two different approaches are proposed [14] when using colour analysis to assess the exposure temperature of concrete after a fire. First, the external surface of the element can be examined; this involves observation of an element's outer walls (in particular, the cement paste). By examining the extent of change in the element's surface colour, the identification of the temperature field can be assessed. However, this method is not feasible if the surface has been affected by smoke or covered with soot.

The other option is to observe the concrete surface where the aggregate is visible. The observation consists of examining the cut surface produced as a result of coring or sawing. These processes reveal aggregate grains, which during heating, often change significantly into more intense red or pink colours [8]. This method is also applicable for surfaces of concrete elements where spalling or flaking takes place. 
Nevertheless, colour change is not directly related to changes in the mechanical and physical properties of concrete, but provides an indicator of the temperature achieved by the concrete during the fire. In practice, several techniques should be combined in order to obtain a sufficiently complete and accurate picture of the damage to the concrete member in question [3]. A correctly conducted assessment process is essential in order to take the right decision on strengthening or carrying out repairs on construction elements affected by fire.

\section{Materials and Testing Procedure}

\subsection{Materials Tested}

The materials tested were ordinary (OC) and high performance (HPC) concrete, mortars and cement pastes. Both concretes consisted of the cement type CEM II/ A-V 42.5R, water and natural riverbed aggregates: $0 \mathrm{~mm}$ to $2 \mathrm{~mm}$ sand; $2 \mathrm{~mm}$ to $8 \mathrm{~mm}$ and $8 \mathrm{~mm}$ to $16 \mathrm{~mm}$ gravel. The mix composition of concretes is presented in Table 1. The mortars and cement pastes were prepared with the same cement and $\mathrm{w} / \mathrm{c}$ (water/cement) ratio as the concretes and using the same components as for concretes. The colour change observations were performed on one sample for each material.

The influence of the heating temperature on mechanical properties of OC and HPC with this mix composition was investigated in a previous publication [14]. In Table 2, relative values of compressive strength for heated concrete cubes with the side of $0.15 \mathrm{~m}$ are presented. Values presented in the table are the average values obtained with 3 cubic samples for each temperature. For more details on samples preparation and heating see [14]. The compressive strength tests were not performed for heated cement pastes and mortars.

\subsection{Testing Procedure}

The colour change observation was performed on the surfaces of the concrete, mortar and cement paste samples. The samples (discs $\varnothing 150 \mathrm{~mm} \mathrm{~h}=50 \mathrm{~mm}$ ) were heated in an electric furnace with a constant heating rate of $1^{\circ} \mathrm{C} / \mathrm{min}$ to reach subsequent temperatures of $\mathrm{T}=100^{\circ} \mathrm{C}, 200^{\circ} \mathrm{C}, 300^{\circ} \mathrm{C}, 400^{\circ} \mathrm{C}, 500^{\circ} \mathrm{C}, 600^{\circ} \mathrm{C}, 700^{\circ} \mathrm{C}$, $800^{\circ} \mathrm{C}, 900^{\circ} \mathrm{C}$ and $1000^{\circ} \mathrm{C}$. After reaching the target temperature samples were heated at this temperature for $1 \mathrm{~h}$ in order to homogenise the temperature within

\section{Table 1}

Concrete mix proportions

\begin{tabular}{lllc}
\hline Constituent & Unit & OC & HPC \\
\hline Cement CEM II/A-V 42,5 R & $\mathrm{kg} / \mathrm{m}^{3}$ & 322 & 478 \\
Water & $\mathrm{dm}^{3} / \mathrm{m}^{3}$ & 193 & 129 \\
w/c & - & 0.6 & 0.27 \\
Sand 0-2 mm & $\mathrm{kg} / \mathrm{m}^{3}$ & 623 & \\
Gravel 2-8 mm & $\mathrm{kg} / \mathrm{m}^{3}$ & 660 & \\
Gravel $8-16 \mathrm{~mm}$ & $\mathrm{~kg} / \mathrm{m}^{3}$ & 550 & \\
\hline
\end{tabular}




\section{Table 2}

Relative values of compressive strength change with the temperature [14]

\begin{tabular}{lcccccc}
\hline $\mathrm{f}_{\mathrm{cT} /} / \mathrm{f}_{\mathrm{c} 20^{\circ} \mathrm{C}}$ & $T=20^{\circ} \mathrm{C}(\%)$ & $200^{\circ} \mathrm{C}(\%)$ & $400^{\circ} \mathrm{C}(\%)$ & $500^{\circ} \mathrm{C}(\%)$ & $600^{\circ} \mathrm{C}(\%)$ & $800^{\circ} \mathrm{C}(\%)$ \\
\hline $\mathrm{OC}$ & 100 & 92 & 78 & 62 & 43 & 19 \\
$\mathrm{HPC}$ & 100 & 93 & 85 & 74 & 57 & 36 \\
\hline
\end{tabular}

the specimen. The temperature was measured with type $\mathrm{K}$ thermocouple placed inside of the furnace, close to the specimen. After cooling, digital images were taken from the sample surfaces with a scanner. A general-purpose flatbed scanner (HP Scanjet G2410) was used and the pictures were taken with a pixel density resolution of 600 ppi. Images of the size $60.071 \mathrm{~mm}$ by $60.071 \mathrm{~mm}$ were cut from the pictures. They were then exported as TIFF raster files into the Scion Image software. The Scion Image package v. 4.0.3, is an image processing and analysis program. It is a freeware tool created to facilitate digital image analysis within the medical sector. Images analysed in Scion are two-dimensional arrays of pixels. All pixels are represented by RGB components, where RGB is an acronym of red, green and blue. Usually the colour space in RGB system is conceived as a cube in the Cartesian coordinate system. Each axis corresponds to the R, G and B component and a colour is defined by three coordinates (R, G, B) where intensities/ values ranges from 0 to 255 . The RGB model is of the additive type, where adding the RGB components produces colours. Thus, point $(255,255,255)$ stands for white and $(0,0,0)$ for black. The observation was based on the RGB colour model because of its widespread use in digital equipment like scanners and computer screens.

In terms of the method proposed for concrete analysis, a digital image is split into three RGB colour components, then presented as a histogram using counts of pixel intensity. The results of the histogram show colour distribution in unheated material and in material heated across a temperature range from $100^{\circ} \mathrm{C}$ to $1000^{\circ} \mathrm{C}$. Histograms from laboratory-heated concrete provide a scale which may be used to determine the temperature actually reached by concrete in a structure. This is done by comparing the scale histograms with the histogram of a sample taken from the structure [14].

The analysis of the results involves a normalisation process where values corresponding to the number of pixels with a specified intensity are divided by the total number of pixels in a given image $\left(\mathrm{N}_{\mathrm{v}}\right)$. Histogram normalisation makes comparison of images with different pixel counts possible. Additionally, this process produces functions that have properties of the probability density function. Histograms can be used to generate a number of parameters defining the properties of this function, including the maximum histogram value, and the colour intensity that is most frequent in a given image. In this research those two parameters were analysed and their evolution with the heating temperature was examined for the three RGB colour components. 


\section{Results}

The impact of heating temperature on the colour change of ordinary and high performance concrete, mortar and cement paste are presented in Figure 1. For ordinary mortar and cement paste the cracking of samples took place at $900^{\circ} \mathrm{C}$ and $500^{\circ} \mathrm{C}$ respectively for ordinary mortar and ordinary cement paste and thus no colour observation above these temperatures were performed. In a picture of cracked cement paste an important increase of black colour intensities appeared, which disrupted the colour analysis.

The normalised histograms $\left(\mathrm{N}_{\mathrm{v}}\right)$ of red, green and blue component intensity obtained in the range of temperatures tested for high performance and ordinary concrete, mortar and cement paste, were then analysed. It was observed that the shape of histograms of RGB colour intensity changes with the temperature of exposition Figures 2, 3, and 4. In general manner the $\mathrm{R}$ and $\mathrm{G}$ intensities move towards higher intensities which correspond to brighter colours. However, the blue colour intensity decreases up to c.a. $400^{\circ} \mathrm{C}$ for both concretes and mortars (Figures 2, 3). Cement pastes change colour, especially HP cement paste, but this change is quite different than for concrete and mortars (Figure 4).

Two parameters were extrapolated from the normalised histogram: the maximum value of $\mathrm{N}_{\mathrm{v}}$, and the more frequent colour intensity for the given picture. This enabled the temperature evolution of those two parameters to be analysed for the red, green and blue components. The results are presented in Figures 5 and 6.

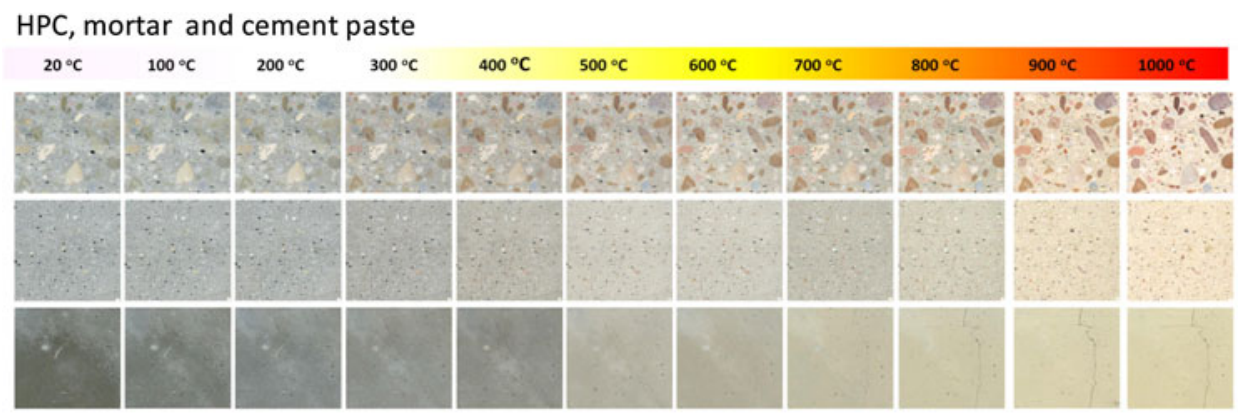

OC, mortar and cement paste

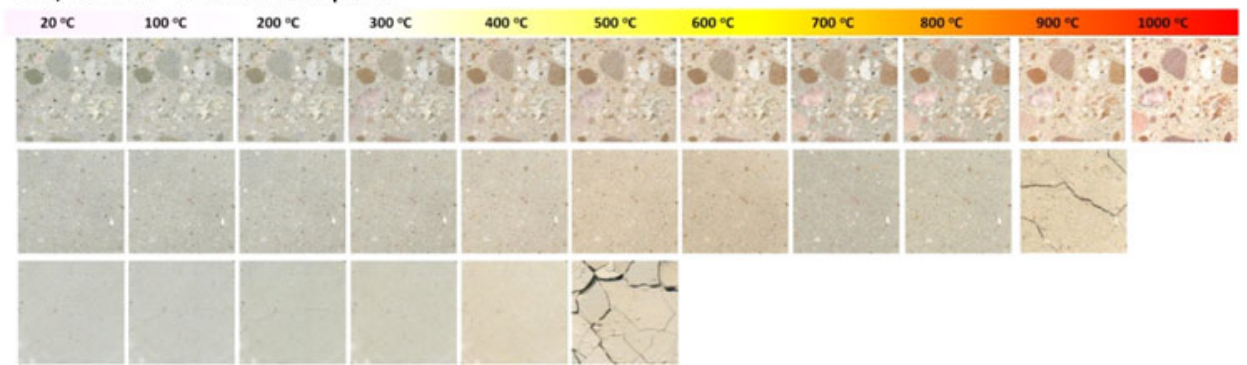

Figure 1. Colour change of high performance and ordinary concrete, mortar and cement paste heated to temperatures ranging from $100^{\circ} \mathrm{C}$ to $1000^{\circ} \mathrm{C}$. 


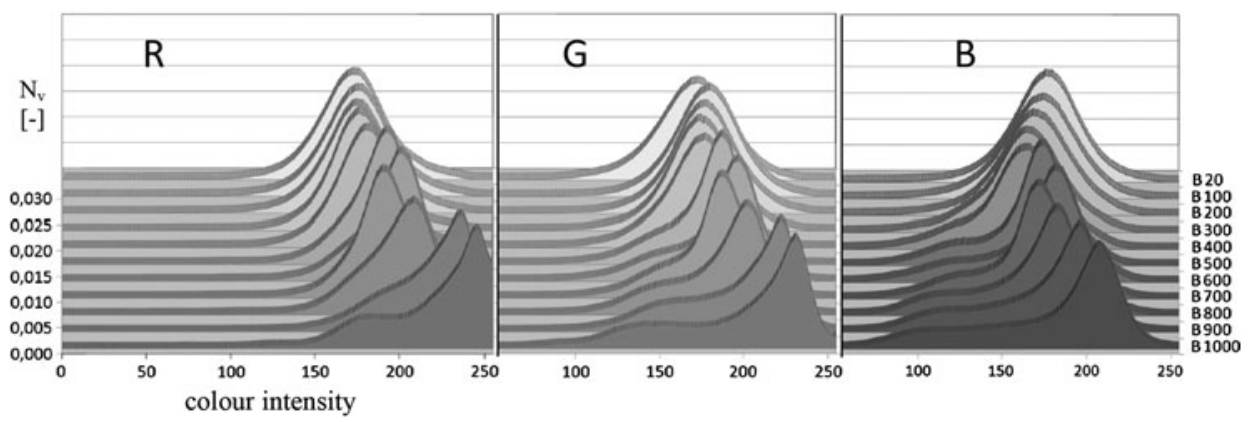

Figure 2. Normalized histograms of RGB colour of high performance concrete, heated to temperatures ranging from $100^{\circ} \mathrm{C}$ to $1000^{\circ} \mathrm{C}$.

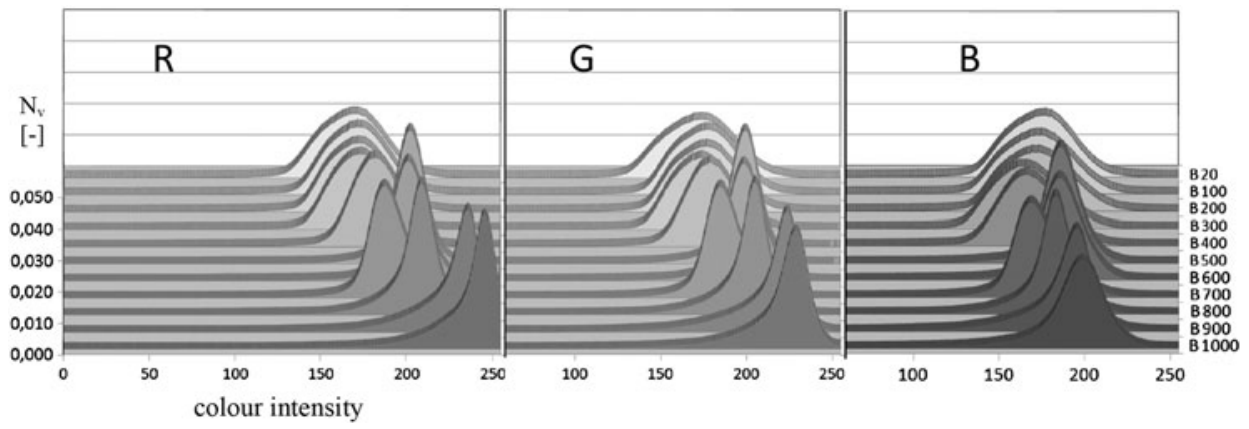

Figure 3. Normalized histograms of the RCB colour of high performance mortar, heated to temperatures ranging from $100^{\circ} \mathrm{C}$ to $1000^{\circ} \mathrm{C}$.

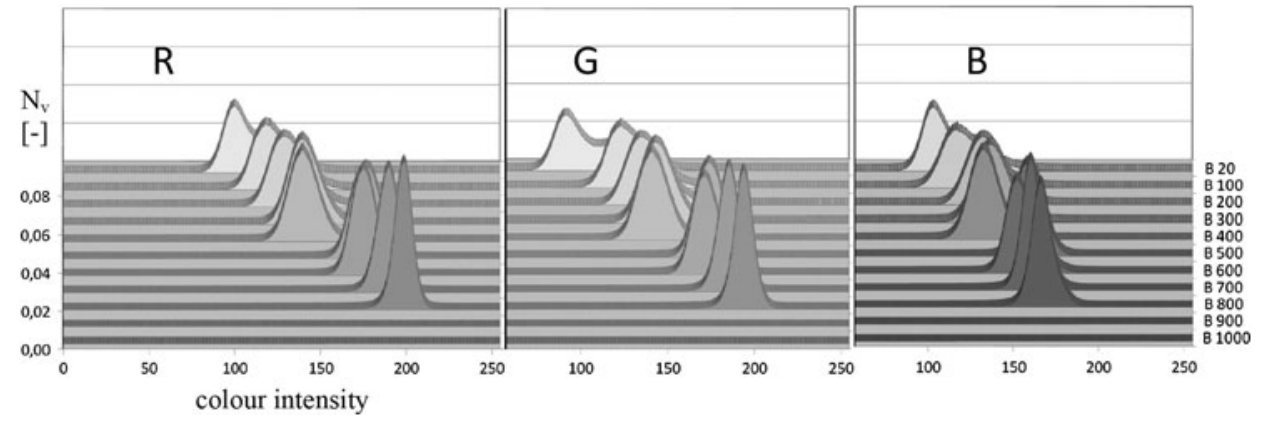

Figure 4. Normalized histograms of RGB colour of high performance cement paste, heated to temperatures ranging from $100^{\circ} \mathrm{C}$ to $800^{\circ} \mathrm{C}$. 

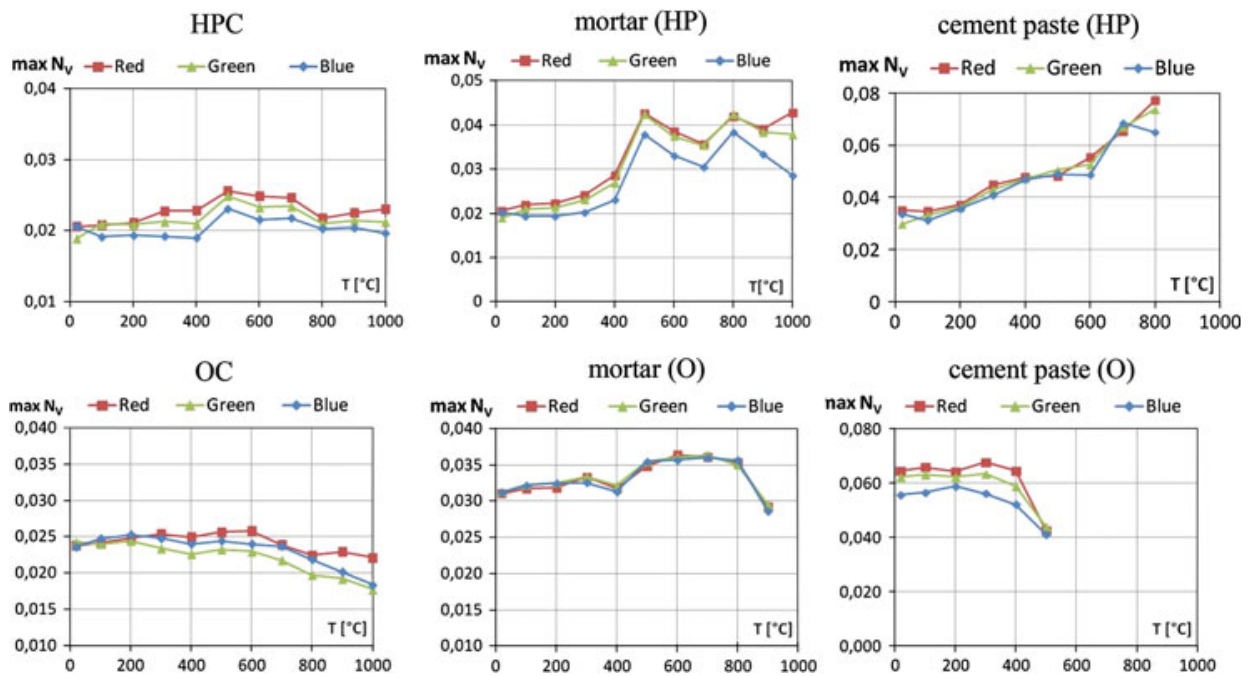

Figure 5. Maximum $\mathrm{N}_{\mathrm{v}}$ values of the red, green and blue components obłained for high performance and ordinary concrete, mortar and cement paste samples in the range of temperatures from $20^{\circ} \mathrm{C}$ to $1000^{\circ} \mathrm{C}$.

It was observed that all curves presenting the maximum histogram value $\left(\mathrm{N}_{\mathrm{v}}\right)$ evolution with the temperature, either for a red, green and blue colour, start from the same point. In Figure 6 for HPC the intensity for which the RGB histogram maximum value appears for all three colours is near to 175 . With an increase in temperature, an increase in red and green colour intensity occurs (Figure 6). On the contrary the blue colour intensity stays below those two values. As a consequence the difference in $\mathrm{R}, \mathrm{G}$ increases compared with values for B occurs, which seems to be a promising factor. However, it is worth noting that the shape of curves for the RGB components analysed present a similar character. This feature is clearly visible for all the materials analysed in Figure 6. For ordinary concrete, the curve for the blue component presents a lower intensity value for maximum $\mathrm{N}_{\mathrm{v}}$ at the reference stage $\left(20^{\circ} \mathrm{C}\right)$ than the other two colour components. This feature can also be found in ordinary mortar and cement paste. This difference between OC and HPC may be attributed to the difference between the watercement ratios. The colour related to the water-cement ratio was analysed in Elsen et al. [15] as a parameter that can be calibrated in order to estimate $w / c$ for an unknown composition of cement paste.

\section{Analysis of Results and the Physical Reasons for Colour Changes in Cementitious Materials}

As illustrated in Figures 5 and 6, both the aggregate and cement matrix undergo colour change when exposed to high temperatures. The general colour changes 

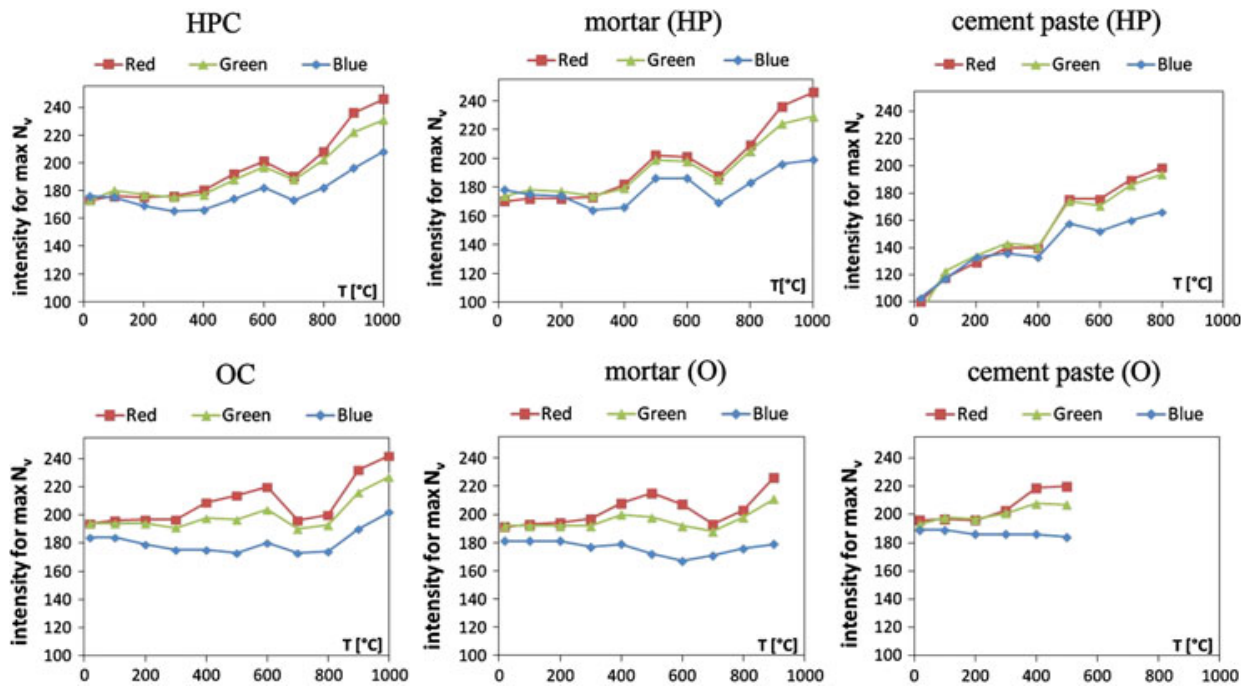

\section{Figure 6. Intensity for the maximum $\mathrm{N}_{\mathrm{v}}$ value of the red, green and blue components obtained for high performance and ordinary con- crete, mortar and cement paste samples in the range of temperatures from $20^{\circ} \mathrm{C}$ to $1000^{\circ} \mathrm{C}$.}

experienced in concrete as a result of heating are linked to the physical and chemical transformations taking place in the heated material. The heating results in the material drying. The order in which water is removed from heated concrete depends on the energy that binds the water and the solid. Thus, free water evaporates first, followed by capillary water, and finally by physically bound water [16]. The first change in colour is linked to the gradual evaporation of water from the cement paste as well as the progressive process of removing water that is chemically bound with cement hydrates. This is visible in the progressive reallocation of the maximum values $\left(\mathrm{N}_{\mathrm{v}}\right)$ in the red, green and blue normalised histograms. As soon as cement paste is heated to a temperature of $500^{\circ} \mathrm{C}$ to $550^{\circ} \mathrm{C}$, portlandite decomposes according to the following reaction: $\mathrm{Ca}(\mathrm{OH})_{2} \rightarrow \mathrm{CaO}+\mathrm{H}_{2} \mathrm{O} \uparrow$ and the its content drops rapidly. The portlandite decomposition reaction explains the increase in $\mathrm{CaO}$ content observed in the cement paste at the temperature of approximately $550^{\circ} \mathrm{C}$ [17]. One of the changes visible at this temperature range is the emergence of a local maximum for the curves of $\mathrm{N}_{\mathrm{v}}$ for the $\mathrm{R}, \mathrm{G}$ and $\mathrm{B}$ component observed for HP concrete and HP cement paste (Figure 5). The $\mathrm{CaO}$ created in this reaction makes the $\mathrm{R}, \mathrm{G}$ and $\mathrm{B}$ colour of the cementitious materials shift in the direction of higher intensity thus creating brighter colours (Figure 6). This observation for the Portland cement element of concrete is critical because the dissociation of portlandite made the concrete practically useless after cooling.

Another vital factor influencing the colour change in concrete following heating is the mineralogical composition of the aggregate. The most pronounced colour change of heated aggregates is observed in those containing minerals with iron 


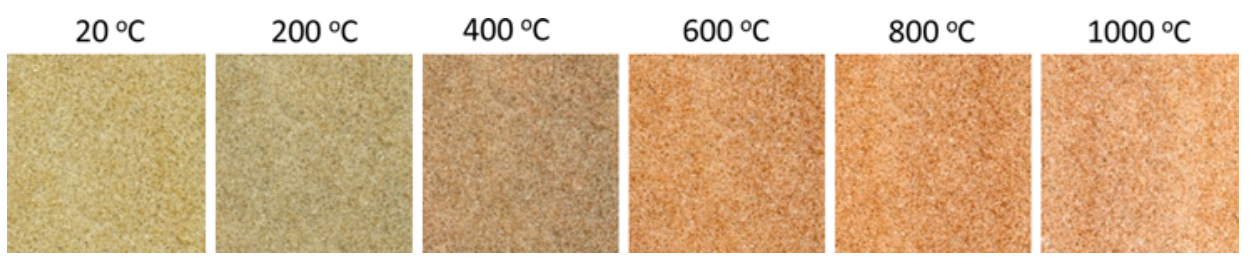

\section{Figure 7. Colour change of sandstone heated to temperatures rang- ing from $200^{\circ} \mathrm{C}$ to $1000^{\circ} \mathrm{C}(60 \times 60 \mathrm{~mm}$ sample $)$.}

compounds such as limonite $\mathrm{FeO}(\mathrm{OH}) \cdot \mathrm{nH}_{2} \mathrm{O}$, hematite $\mathrm{Fe}_{2} \mathrm{O}_{3}$, jarosyte and goethite. Ferrous salts and amorphous iron hydroxides present in the aggregate oxidize with temperature. The temperature of this transformation is in the range of $250^{\circ} \mathrm{C}$ to $300^{\circ} \mathrm{C}[6,7,12]$.

Sandstone with clay and locally with a clayey-ferruginous binder, subjected to a high temperature episode produces an appearance with an intensive red coloration, as can be seen in Figure 7.

The same technique of sample scanning, a surface of a sandstone sample (surface dimensions $60 \times 60 \mathrm{~mm}$ ) subjected to heating are presented in Figure 7 . The red colouration appears on the sample heated above $200^{\circ} \mathrm{C}$.

Microscopic observations of non heated sandstone samples in polarised light revealed the presence of amorphous iron hydroxides in the space between the quartz grains (Figure 8). Moreover, the crystalline form of iron oxides with reddish-brown colouration was observed following heating (shown in Figure 9).

In the riverbed aggregates composition used in this study, not only sandstones, but also the grains with a carbonate character (limestone or dolomite) were present. For those grains change in colour takes place at a temperature of around $700^{\circ} \mathrm{C}$ where a local minimum may be distinguished on the curves presented in Figure 6. At temperatures above $700^{\circ} \mathrm{C}$, carbonate aggregate decomposes into $\mathrm{CaO}$ and $\mathrm{CO}_{2}$ resulting in a brighter colours appearance related to the lime whitish tint.

Aggregates occupy $70 \%$ to $80 \%$ of the volume of concrete and thus heavily influence its behaviour at high temperature. By consequence, colour change of concrete will depend largely on the mineralogical composition of aggregate used for its manufacturing.

The use of thermal analysis, including differential thermal analysis and derivative thermogravimetry, allows one to describe the reactions that occur in cement paste and concrete with an increase of temperature. An example of DTA/TGA observations derived from [1] presents similar temperature regions where peaks corresponding to the colour change appear (Figure 10). The subsequent changes may be distinguished in the following order: first the evaporable and the bound water are lost from the material, than portlandite decomposes, and finally calcium carbonate decomposes [1, 15].

A validation of aforementioned technique, using RGB colour scale was also carried out. To validate the consistency of the method, a HP concrete sample of the same composition was heated to the temperature of $350^{\circ} \mathrm{C}$ then the colour 

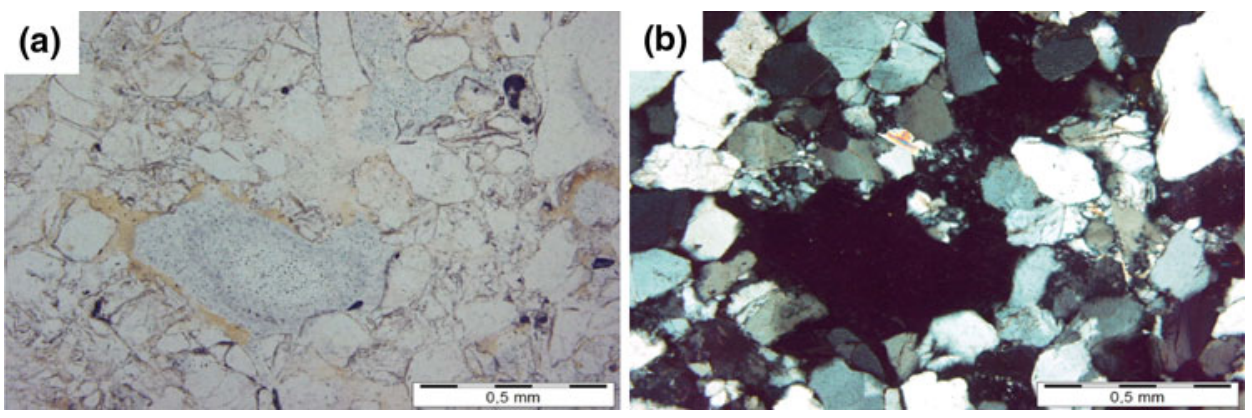

Figure 8. Sandstone $\mathrm{T}=20^{\circ} \mathrm{C}$, magnification $80 \times$, (a )amorphous iron hydroxides (yellow-brown) lining the pore space, one nicol, (b) undeveloped pore space (black) partially filled with amorphous iron hydroxides, crossed-polarised light.
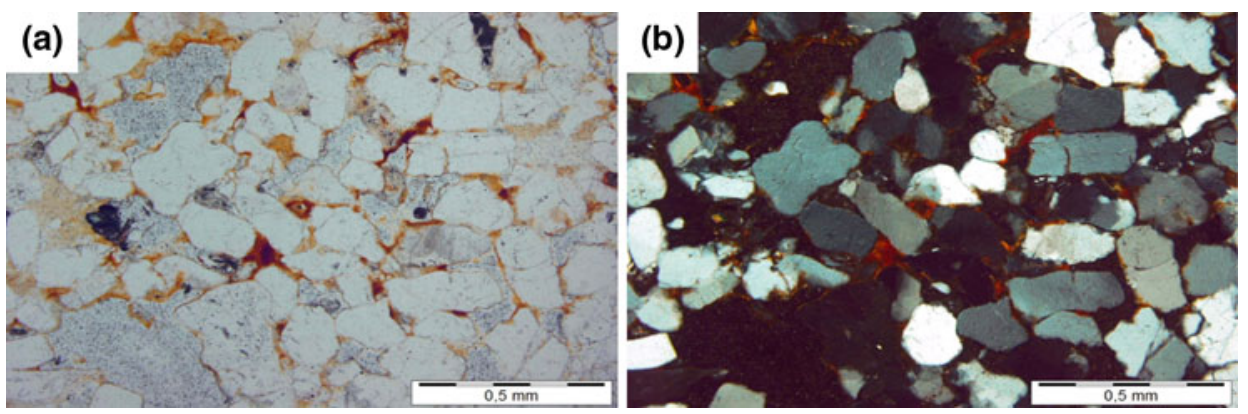

Figure 9. Sandstone $\mathrm{T}=800^{\circ} \mathrm{C}$, magnification $80 \times$, (a) crystalline iron oxides (reddish-brown) and undeveloped pore space (grey) bełween quartz grains, one nicol, (b) undeveloped pore space (black) partially filled with crystalline iron oxides (reddish interference colours), crossed-polarized light.

analysis was performed. The normalised histogram of red green and blue component was compared to the RGB colour scale indicating that the heating temperature was in the range between $300^{\circ} \mathrm{C}$ and $400^{\circ} \mathrm{C}$. Also the investigations on concrete specimen heated in transient heating conditions, heated from one side, were performed and described in detail in [14]. The specimen side surface was scanned producing an image which was divided into strips sized $20 \mathrm{~mm}$ by $60 \mathrm{~mm}$. RGB component histograms were obtained and normalised using the image analysis procedure described above. The result was compared with a prepared scale. The comparison allowed revealing the exposition temperature in each $20 \mathrm{~mm}$ wide strip. In this case the validation was made on a concrete element external surface; this involves the observation of an element's outer walls (in particular, the cement paste). 


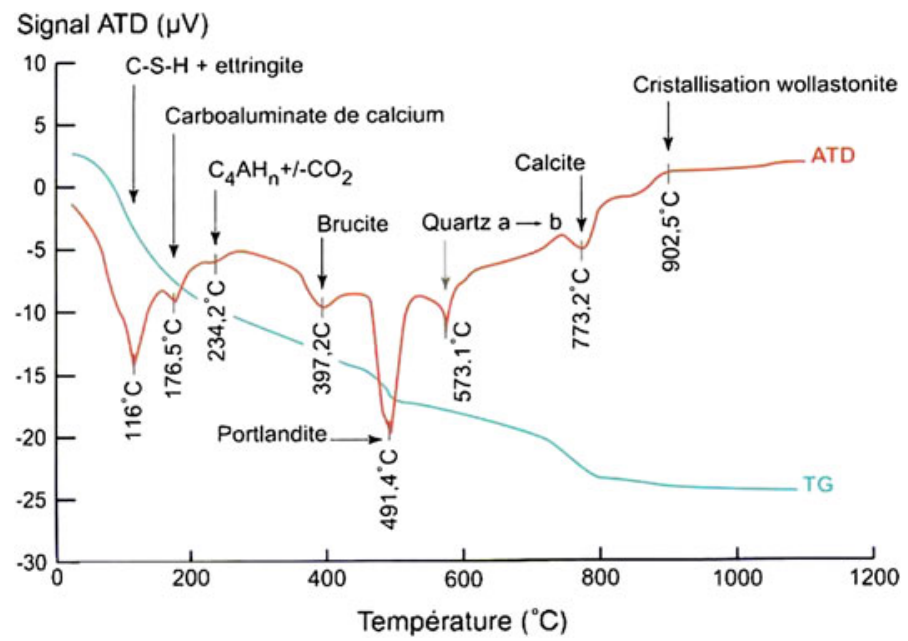

Figure 10. TGA DTA of concrete [ 10$]$.

\section{Conclusions and Perspectives}

During a real fire, temperatures within a section of concrete do not generally reach equilibrium values. A thermal gradient is established where the temperature of the outside layers is drastically increased, while the temperatures of the inner concrete may be relatively low. The method described in the paper is a contribution to the application of colour analysis to the estimation of the maximum temperature to which a concrete is exposed when subjected to fire. A scanner seems to be a useful and simple tool for making digital images of samples/cores resulting in guaranteed consistent lighting conditions. A similar degree of usefulness and simplicity was established with regard to the colour analysis using the RGB model which has been developed and the readily available software package Scion Image.

The proposed method was applied for heated ordinary and high performance concretes, mortars and cement pastes. The observations revealed an important colour evolution of tested materials caused by heating. The main reasons of those changes were attributed to the physical and chemical transformations taking place within the main constituents: cement paste and aggregates. Type and mineralogical composition of the aggregates (i.e. siliceous, calcareous) plays an important role in overall colour change of heated concrete due to their important volume in concrete, exceeding $70 \%$. As it was observed in this study, the aggregates that contain minerals with iron compounds undergo pronounced colour change when heated to the temperature above $250^{\circ} \mathrm{C}$. The ferrous components (i.e. minerals like limonite, hematite, jarosyte and goethite) oxidation was confirmed by microscopic observations in polarised light. In sandstone samples with a clayey-ferruginous binder subjected to $800^{\circ} \mathrm{C}$ the presence of oxidized particles responsible for the reddish coloration was found. 
By heating samples of concrete, mortar and cement paste specimens a colour scales were obtained by taking images of samples heated to temperatures across the $100^{\circ} \mathrm{C}$ to $1000^{\circ} \mathrm{C}$. By comparing normalised histograms of a heated concrete specimen with scale, or by comparing studied parameters (maximum histogram value $\mathrm{N}_{\mathrm{v}}$ and the intensity corresponding to the maximum value $\mathrm{N}_{\mathrm{v}}$ ) seem to be a useful tool for estimating the temperature to which concrete has been exposed during fire. In practice, several techniques should be combined in order to obtain a sufficiently complete and accurate picture of the damage to the concrete member in question.

Currently this research continues in order to provide consistent parameters that allow the maximum temperature estimation without the necessity of a full calibration scale to be determined. In particular, there is a need to establish the parameter that change in a similar manner for a one type of concrete (i.e. one type of aggregate). The researched method would allow determining the exposition temperature of the heated concrete on the basis of its digital image and calibrated parameter that will be established with the use two images: of pristine concrete, and the sample heated into the temperature $T$.

As a perspective the colour change observations for concretes with different type of aggregates granite, basalt and dolomite are in progress. As the first results have shown a type of cement will also be the great importance.

\section{Acknowledgment}

The study was supported by the Polish National Research Centre Grant N N506 045040 .

\section{Open Access}

This article is distributed under the terms of the Creative Commons Attribution License which permits any use, distribution, and reproduction in any medium, provided the original author(s) and the source are credited.

\section{References}

1. LCPC NO 62 (2005) Présentation des techniques de diagnostic de l'état d'un béton soumis à un incendie. Laboratoire Central des Ponts et Chaussées, Paris, France, p 114

2. Assessment, Design and Repair of Fire-Damaged Concrete Structures (2008) Technical report no 68. The Concrete Society, London, p 80

3. Felicetti R (2011) Assessment methods of fire damages in concrete tunnel linings. Fire Technol. doi:10.1007/s10694-011-0229-6

4. Ketterings QM, Bigham JM (2000) Soil color as an indicator of slash-and-burn fire severity and soil fertility in Sumatra, Indonesia. Soil Sci Soc Am J 64:1826

5. BRE (1950) Technical paper no 4

6. Chakrabarti B, Yates T, Lewry A (1996) Effect of fire damage on natural stonework in buildings. Constr Build Mater 10(7):539-544 
7. Hajpal M (2002) Changes in sandstones of historical monuments exposed to fire or high temperature. Fire Technol 38(4):373-382

8. Short NR, Purkiss JA, Guise SE (2001) Assessment of fire damaged concrete using colour image analysis. Constr Buil Mater 15:9-15

9. Bessey GE (1950) The visible changes in concrete or mortar exposed to high temperatures. Investigations on building fires, Part 2, national building studies technical paper no 4. HMSO, London, pp 6-18

10. Felicetti R (2004) Digital camera colorimetry for the assessment of fire-damaged concrete. In: Gambarova PG, Felicetti R, Meda A, Riva P (eds) Proceedings of the workshop: fire design of concrete structures: what now? what next? fib task group 4.3. Fire design of concrete structures, Milan, pp 211-220

11. Luo HL, Lin DF (2007) Study the surface color sewage sludge mortar at high temperature. Constr Build Mater 21:90-97

12. Annerel E, Taerwe L (2009) Revealing the temperature history in concrete after fire exposure by microscopic analysis. Cem Concr Res 39(12):1239-1249

13. Piasta J (1989) Heat deformation of cement phases and microstructure of cement paste. Mater Struct 17(102):415-420

14. Hager I (2010) The application of RGB histogram analysis of colour images as a method of assessing the condition of concrete in structures after fire. In: Proceedings of 6th international conference on structures in fire (SIF2010), June 2-4, 2010, Michigan, USA, pp 841-847

15. Elsen J, Lens N, Aarre T, Quenard D, Smolej V (1995) Determination of the w/c ratio of hardened cement paste and concrete samples on thin sections using automated image analysis techniques. Cem Concr Res 25:827-834

16. Baroghel-Bouny V (1994) Caractérisation des pâtes de ciment et des béton. Méthodes, analyse, interprétations. LCPC, p 470

17. Castellote M, Alonso C, Andrade C, Turrillasa X, Campoc J (2004) Composition and microstructural changes of cement pastes upon heating, as studied by neutron diffraction. Cem Concr Res 34:1633-1644 